\title{
Synthesis of large CZTSe nanoparticles through a two-step hot-injection method
}

\author{
Engberg, Sara Lena Josefin; Li, Zhenggang; Lek, Jun Yan; Lam, Yeng Ming; Schou, Jørgen
}

Published in:

RSC Advances

Link to article, DOI:

10.1039/c5ra21153k

Publication date:

2015

Document Version

Peer reviewed version

Link back to DTU Orbit

\section{Citation (APA):}

Engberg, S. L. J., Li, Z., Lek, J. Y., Lam, Y. M., \& Schou, J. (2015). Synthesis of large CZTSe nanoparticles through a two-step hot-injection method. RSC Advances, 5, 96593-96600. https://doi.org/10.1039/c5ra21153k

\section{General rights}

Copyright and moral rights for the publications made accessible in the public portal are retained by the authors and/or other copyright owners and it is a condition of accessing publications that users recognise and abide by the legal requirements associated with these rights.

- Users may download and print one copy of any publication from the public portal for the purpose of private study or research.

- You may not further distribute the material or use it for any profit-making activity or commercial gain

- You may freely distribute the URL identifying the publication in the public portal 


\title{
Synthesis of large CZTSe nanoparticles through a two-step hot-injection method
}

\author{
Sara Engberg ${ }^{* 1 \dagger}$, Zhenggang $\mathrm{Li}^{* 2}$, Jun Yan Lek ${ }^{2}$, Yeng Ming Lam², and Jørgen Schou ${ }^{1}$ \\ ${ }^{1}$ DTU Fotonik, Technical University of Denmark, DK-40oo Roskilde, Denmark, ${ }^{2}$ School of Materials Science and \\ Engineering, Nanyang Technological University, 50 Nanyang Avenue, 639798, Singapore \\ * These authors contribute equally. ${ }^{\dagger}$ Corresponding author.
}

Keywords: CZTS, CZTSe, Nanoparticles, Hot-injection

Supporting Information Placeholder

\begin{abstract}
Grain boundaries in $\mathrm{Cu}_{2} \mathrm{ZnSn}\left(\mathrm{S}_{\mathrm{x}} \mathrm{Se}_{1-\mathrm{x}}\right)_{4}$ (CZTSSe) thin films act as a defect that reduces the mobility of the charges. Hence one way to improve the performance of these thin film solar cells is to increase the grain size in the films. Most of the synthesis methods published so far for CZTSSe colloidal nanoparticles can achieve a general size distribution range from $5-20 \mathrm{~nm}$. This is where the particle size will saturate for most recipes used today. The assumption is that uniform size distribution is good for grain growth in a thin film but based on packing considerations, an optimal mixture of large and small nanoparticles that can easily be dispersed in non-polar solvents could be better. $\mathrm{Cu}_{2} \mathrm{ZnSnS}_{4}$ (CZTS) and $\mathrm{Cu}_{2} \mathrm{ZnSnSe}_{4}$ (CZTSe) nanoparticles are synthesized using the hot-injection method with oleylamine, trioctylphosphine, and hexadecane as the solvents. Selenium (Se) is introduced in the liquid phase to encourage grain growth - liquid selenization. This eliminates the need to anneal the film in a Se-containing atmosphere and allows for a more environmentally friendly process with lower temperatures and shorter annealing times. We show that a good dispersion can be achieved by choosing suitable surfactant molecules, solvents and precursors, and by controlling the initial monomer concentration. Additionally, we show how our new synthesis route can be utilized to achieve targeted ratios of CZTS and CZTSe nanoparticles to be used for mixed-phase CZTSSe thin films.
\end{abstract}

\section{Introduction}

$\mathrm{Cu}_{2} \mathrm{ZnSn}\left(\mathrm{S}_{\mathrm{x}} \mathrm{Se}_{1-\mathrm{x}}\right)_{4}$ (CZTSSe) has shown to have great potential as a non-toxic, earth-abundant absorber material for thin film solar cell applications. This was recently demonstrated by Wang et al. ${ }^{1}$, who achieved an efficiency of $12.6 \%$. A high absorption coefficient of more than $10^{4} \mathrm{~cm}^{-1}$ and a band gap ranging from $1 \mathrm{eV}$ to $1.5 \mathrm{eV}$ are some of the properties making it an interesting material for solar energy conversion. On top of this, another reason for the increasing interest in this material is that its properties closely resemble the commonly used quaternary solar cell material $\mathrm{CuIn}_{\mathrm{y}} \mathrm{Ga}_{1-y} \mathrm{Se}_{2}$ (CIGS) but without any relatively rare metals such as In and $\mathrm{Ga}$.
The record power conversion efficiency of a pure sulfide phase CZTS ( $\mathrm{x}=1)$ solar cell is $8.8 \%,{ }^{2}$ and the record efficiency of a pure selenide CZTSe $(\mathrm{x}=0)$ solar cell is $11.6 \% .^{3}$ The combination of sulfide and selenide in the composition improves the efficiency because selenium facilitates grain growth and offers the possibility to tune the band gap of the final film. There are many different theories trying to explain the former observation and one such theory suggests that Se replaces sulfur (S) in the crystal lattice during the annealing process and this results in the expansion of the lattice since the Se atom (1.98 $\AA$ ) is larger than the S atom (1.84 $\AA$ ). This in turn causes a volume expansion which leads to the elimination of voids and results in the formation of a dense film with fewer grain boundaries. ${ }^{4}$

There are several techniques being used to achieve a mixed sulfide/selenide phase: (1) annealing CZTS in Se, (2) annealing CZTSe in $\mathrm{S}$ or $\mathrm{H}_{2} \mathrm{~S}$, ${ }^{1}$ or (3) co-depositing a mixed-phase material. ${ }^{5}$ The main fabrication methods are divided into either vacuum or non-vacuum processing techniques, where vacuum techniques lead to good control over film composition but often is more expensive due to elaborate equipment and processing time.

Wet-chemical synthesis and the solution deposition route for CZTSSe are attractive for large-scale fabrication. One should make a distinction between the nanoparticle (NP) ink and the precursor ink approach where a direct coating with precursors holds the record efficiency, $\eta$, of $\eta=12.6 \%$. The success of this cell originates from the small non-organic hydrazinium cation, which mixes well with all elements involved. ${ }^{6}$ However, the highly reactive and toxic nature of hydrazine limits the practicality of this approach. Caution should be taken when handling this non-user-friendly solvent. Thus, the use of pre-synthesized NPs without the need for a toxic reducing agent is a major advantage. Various alternatives to hydrazine do exist, and several organic solvents can be utilized. ${ }^{4,-10}$ However, none was able to reach an efficiency close to the hydrazine route.

Nanoparticle deposition methods such as doctor blading $(\eta=9 \%(\text { CZTSSe }))^{7}$, spin coating $(\eta=7.7 \%(\text { CZTSSe }))^{8}$, spray coating $(\eta=1.4 \%(\text { CZTSe }))^{9}$, drop casting $(\eta=0.74 \%(\text { CZTSSe }))^{4}$ 
and ink-jet printing $(\eta=4.46 \%(\text { CZTSSe }))^{10}$ have been attempted by many groups. The best device of pure phase CZTS NPs has an efficiency of $2.5 \%{ }^{11}$. The main challenge with the NP approach is the presence of organic molecules used as the solvent and/or surfactant; it restricts crystal growth or increases the resistivity of the deposited film as a result of the organic molecules. ${ }^{9}$ Another common observation as a result of the organic molecules in the film is a carbon-rich layer separating the back-electrode Mo-layer from the large-grained CZTS-layer. This suggests that with large amounts of organic ligands, annealing does not necessarily result in the sintering of the surfactant-coated NPs but instead it causes an out-diffusion of cations from the NPs in the film and new CZTS grains on top of the carbon-rich film. ${ }^{12}$ This carbon-rich layer can increase the series resistance and act as a barrier for charge transport, ${ }^{12}$ or it can protect the layer so that it remains conductive. ${ }^{13}$ Nonetheless, the presence of the surfactant is necessary for solubility, and the prospects of this approach are brighter if the amount of organics in the film is limited. To achieve this, several means are pursued - ligand exchange, ${ }^{8,9}$ control of solvent/surfactant mixture during the annealing step, utilizing shorter chain ligands or no ligands at all (e.g. through a polar solvent synthesis), and post-annealing. Synthesis of larger NPs is a route that can reduce the amount of surfactants (since larger NPs have a smaller surface-to-volume-ratio and thus less ligands present) and on top of this, high efficiencies of $7.4 \%$ have be shown by the monograin solar cell approach $^{14}$. If the NPs were larger, less grain growth would be required. This could mean lower annealing temperatures and shorter annealing times, and perhaps that the need for annealing in a more toxic Se-atmosphere is circumvented.

Until now, the focus has been on synthesizing NPs in the range of 5 to $20 \mathrm{~nm}$, as showed in Table 1 . Most groups have attempted to produce a narrow size distribution in order to form a compact film. ${ }^{15}$ The most commonly used methods are the hot-injection (or one-pot) and the solvothermal method. The solvothermal method can result in particles of hundreds of nanometers, however, the crystallite domain size obtained from the XRD pattern is considerably smaller (Table 1). ${ }^{13,16-21}$ Zaberca et al. ${ }^{18}$ find that the large particles are only partially crystallized. The best solar cell efficiencies have been obtained for nanoparticles synthesized through the hot-injection approach ${ }^{7}$, and for NPs synthesized through hot-injection, the average particle size is closer to the crystallite size. .,5,7,9,11,22-34 $^{-1}$

Previous NP syntheses suggest that larger particle sizes can be obtained through longer reaction duration ${ }^{27}$ and using chalcogenide precursors with slower reaction rates ${ }^{29}$ but so far these changes only resulted in anisometric particles of $\sim 40 \mathrm{~nm}$ (in length) and $\sim 25 \mathrm{~nm}$ (in diameter). Zhou et al..$^{30}$ find that the particle size increased at higher reaction temperatures - with $8 \mathrm{~nm}$ at $240^{\circ} \mathrm{C}$ and $16 \mathrm{~nm}$ at $280^{\circ} \mathrm{C}$. In other fields of nanotechnology, larger particles have been synthesized by controlling the ligand-particle interaction and the number of nuclei initially formed ${ }^{36,37}$ based on a paper by Yin and Alivatos ${ }^{38}$. Here we make use of one of these ideas to design an alternative method to increase the particle size. We hypothesize that we can control the monomer
Table 1. Overview of NP size synthesized through the solvothermal or hot-injection/one-pot methods. ${ }^{\dagger}$

\begin{tabular}{|c|c|c|c|}
\hline$\eta(\%)$ & $\begin{array}{c}\text { Average } \\
\text { particle } \\
\text { diameter } \\
(\mathrm{nm})\end{array}$ & $\begin{array}{c}\text { Crystallite } \\
\text { domain } \\
\text { size }(\mathbf{n m})\end{array}$ & Reference \\
\hline
\end{tabular}

\begin{tabular}{|c|c|c|c|}
\hline \multicolumn{4}{|c|}{ Solvothermal method } \\
\hline \multirow{7}{*}{1.94} & $5-10$ & 4.95 & Cao $(2010)^{13}$ \\
\hline & $100-150$ & 8 & Zhou(2011) ${ }^{16}$ \\
\hline & 119.7 & 10 & $\operatorname{Xie}(2011)^{17}$ \\
\hline & 200 & $5-20$ & Zaberca(2012) ${ }^{18}$ \\
\hline & 10 & 11.3 * & $\operatorname{Tian}(2012)^{19}$ \\
\hline & $20-3,000$ & $<10$ & Zhou(2013) $)^{20}$ \\
\hline & $40-60$ & 16.2 * & Chalapathy $(2013)^{21}$ \\
\hline
\end{tabular}

\begin{tabular}{|c|c|c|c|}
\hline \multicolumn{4}{|c|}{ Hot-injection or one-pot method } \\
\hline & $12.8 \pm 1.8$ & 12.9 * & Riha(2009) ${ }^{22}$ \\
\hline 7.2 & $15-25$ & 12.8 * & $\operatorname{Guo}(2010)^{4}$ \\
\hline \multirow[t]{19}{*}{0.23} & $10.6 \pm 2.9$ & $7 \cdot 7^{*}$ & Steinhagen $(2010)^{23}$ \\
\hline & $20.0 \pm 2.0$ & 23 & Shavel(2010) ${ }^{24}$ \\
\hline & $2 \pm 12 \%$ & 3.1 * & Khare $(2011)^{25}$ \\
\hline & $2.5 \pm 10 \%$ & 3.1 * & \\
\hline & $5 \pm 23 \%$ & 5.0 * & \\
\hline & $7 \pm 20 \%$ & 8.6 * & \\
\hline & 17 & $15 \cdot 7$ & $\operatorname{Zou}(2011)^{26}$ \\
\hline & $7.8 \pm 1.6$ & $7 \cdot 5 \pm 0.6$ & $\operatorname{Riha}(2011)^{5}$ \\
\hline & $8.4 \pm 1.7$ & $10.2 \pm 0.7$ & \\
\hline & 40 & $23.0 *$ & $\operatorname{Li}(2012)^{27}$ \\
\hline & $35 \cdot 11$ & 18.0 * & $\operatorname{Singh}(2012)^{28}$ \\
\hline & 7-10 & 7 & $\operatorname{Rath}(2012)^{29}$ \\
\hline & $14-18$ & 18 & \\
\hline & $25-35$ & 23 & \\
\hline & $15^{-25}$ & 13 & \\
\hline & $15-25$ & 18 & \\
\hline & 8 & 4.9 * & Zhou(2013) $)^{30}$ \\
\hline & 12 & $7.8 *$ & \\
\hline & 16 & 14.8 * & \\
\hline \multirow[t]{3}{*}{1.4} & $25 \pm 5$ & No $X R D$ & Carreta $(2013)^{9}$ \\
\hline & $9 \cdot 9 \pm 2.6$ & $4.6^{*}$ & $\operatorname{Hou}(2013)^{31}$ \\
\hline & $9 \cdot 7 \pm 1.1$ & $4.5 *$ & \\
\hline \multirow[t]{4}{*}{9.0} & $12.51 \pm 7.94$ & $11.7^{*}$ & $\operatorname{Miskin}(2014)^{7}$ \\
\hline & $17 \cdot 3 \pm 1.3$ & $9.0^{*}$ & $\operatorname{Li}(2014)^{32}$ \\
\hline & $13.5 \pm 2.9$ & 12.3 * & \\
\hline & $19.8 \pm 6.5$ & 10.3 & $\operatorname{Li}(2014)^{33}$ \\
\hline 2.5 & 60 & 20 & $\operatorname{Mkawi(2014)}{ }^{11}$ \\
\hline 2.0 & $12.2 \pm 1.1$ & 13.6 & $\mathrm{Gu}(2015)^{34}$ \\
\hline
\end{tabular}

${ }^{\dagger}$ The particle sizes are estimated from TEM images. The crystallite domain size is calculated from the Scherrer equation $^{35}$ from the FWHM of the main (112) peak in the XRD pattern. *If the crystallite domain size was not given, we have estimated it from the XRD pattern, using $K=0.9$ (approximation for spherical particles). $K$ is a constant in the Scherrer equation. 
concentration by first synthesizing CZTS NPs, and subsequently supplying Se to the synthesis process. Se is usually incorporated during annealing to increase grain growth. However, in this work Se is added in the liquid phase and this can be classified as a form of liquid selenization. We show that the particle growth in the liquid phase is possible when we choose suitable surfactant molecules, solvents and precursors, and this new synthesis route can achieve targeted ratios of CZTS and CZTSe NPs for mixed-phase CZTSSe thin films.

\section{Experimental details}

Copper(II) acetate $\left(\mathrm{Cu}(\mathrm{OAc})_{2}\right.$, Sigma-Aldrich, 98\%), zinc chloride anhydrous $\left(\mathrm{ZnCl}_{2}\right.$, Sigma-Aldrich, 99.99\%), tin(IV) chloride pentahydrate $\left(\mathrm{SnCl}_{4} \cdot 5\left(\mathrm{H}_{2} \mathrm{O}\right)\right.$, Sigma-Aldrich, $\left.98 \%\right)$, sulfur powder (S, Sigma-Aldrich), selenium powder (Se, Kanto Chemicals), hexadecane (Sigma-Aldrich, 99\%), trioctylphosphine (TOP, Strem Chemical), and oleylamine (OLA, Sigma-Aldrich, 70\%) were purchased and used as received.

Methodology. The synthesis consists of two steps: (1) synthesis of CZTS NPs and (2) conversion of CZTS NPs into CZTSe NPs.

Synthesis of $\mathrm{Cu}_{2} \mathrm{ZnSnS}_{4}$ nanoparticle ink. In a typical synthesis, $0.5 \mathrm{mmol} \mathrm{Cu}(\mathrm{OAc})_{2}, 0.32 \mathrm{mmol} \mathrm{ZnCl}_{2}$ and 0.25 mmol $\mathrm{SnCl}_{4} \cdot{ }_{5}\left(\mathrm{H}_{2} \mathrm{O}\right)$ were combined in a three-neck flask with $5 \mathrm{~mL}$ OLA. The mixture was degassed under vacuum for $20 \mathrm{~min}$ while heated and stirred. The flask was purged with $\mathrm{N}_{2}$, and once the temperature reached $150^{\circ} \mathrm{C}$, the mixture was allowed to react for 20 min until the color changed from blue to clear yellow. In the meantime, $1 \mathrm{ml}$ of a $1 \mathrm{M} \mathrm{S}$ in OLA solution was prepared and stirred until all the $S$ was completely dissolved, and the solution turned into a brownish red color. After formation of the clear yellow $\mathrm{Cu}-, \mathrm{Zn}$-, Sn-complex, the temperature was increased and once it reached $220^{\circ} \mathrm{C}$, the $\mathrm{S}$ solution was rapidly injected. The typical reaction time was $30 \mathrm{~min}$, followed by water bath-cooling.

The NPs were dispersed in toluene and sonicated to increase solubility. Ethanol was added as anti-solvent and the solution was centrifuged for $20 \mathrm{~min}$ at 8 ,ooo rpm. The solvent was decanted, and the CZTS NPs were redispersed in 1 $\mathrm{ml}$ OLA and $15 \mathrm{ml}$ hexadecane and sonicated for 20 min to ensure complete dissolution for the second step of the reaction.

Liquid phase conversion of $\mathrm{Cu}_{2} \mathrm{ZnSnS}_{4}$ nanoparticles to $\mathrm{Cu}_{2} \mathrm{ZnSnSe}_{4}$ nanoparticles. The solution was degassed under vacuum for $20 \mathrm{~min}$ while heated to $\sim 100^{\circ} \mathrm{C}$ under constant stirring. The mixture was purged with $\mathrm{N}_{2}$ and the temperature was raised to $\sim 250^{\circ} \mathrm{C}$. Meanwhile, $3 \mathrm{ml}$ of $1.33 \mathrm{M} \mathrm{Se}$ in TOP solution was heated to $150^{\circ} \mathrm{C}$ under constant stirring while being purged with $\mathrm{N}_{2}$. Once the CZTS NP solution reached $250^{\circ} \mathrm{C}$, the Se-solution was quickly injected, and the reaction was allowed to occur for the desired amount of time, typically $30 \mathrm{~min}$. The reaction was stopped when the solution was cooled in a water bath, and the wash/precipitation step was repeated three times as described for the CZTS NPs.

Characterization. The crystallinity of the NPs was determined with powder X-ray Diffraction (XRD) from Bruker D8 Advance, with a $\theta / 2 \theta$ scan at a speed of $0.75^{\circ} / \mathrm{min}$, sampling pitch of $\mathrm{O} .02^{\circ}$, and $\mathrm{Cu} \mathrm{K \alpha}$-radiation $(\lambda=0.15418 \mathrm{~nm})$. The
Raman analysis was performed using a Renishaw inVia Raman microscope with a $532 \mathrm{~nm}$ laser. Transmission electron microscopy (TEM) images from JEOL TEM $2100 \mathrm{~F}$ were used for the morphology analysis. The stoichiometry was found either using a field emission scanning electron microscope (FESEM), JEOL 76ooF, for large assemblies of particles, or using scanning transmission electron microscopy energy dispersive X-ray spectroscopy (STEM-EDS) in the JEOL TEM 210oF for local composition data.

\section{Results and Discussion}

Larger grain size in CZTSSe thin films is desirable for its application as an absorber in thin film solar cells, and could be obtained by starting out with larger NPs. When synthesizing large NPs, there are many factors that will affect the growth, for instance time, temperature, and the amount of injected Se. In this work, we seek to understand the impact of these factors on particle growth while injecting Se precursors into a solution of pre-synthesized CZTS NPs. In order to be able to control the growth, we look at the transformation at different reaction times ( $2 \mathrm{~min}, 5 \mathrm{~min}, 10 \mathrm{~min}, 20 \mathrm{~min}, 30$ $\min , 1 \mathrm{hr}, 2 \mathrm{hr}$, and $4 \mathrm{hr}$ ), and with different concentrations of injected Se (o M, o.66 M, 1.33 M, and $2 \mathrm{M}$ ).

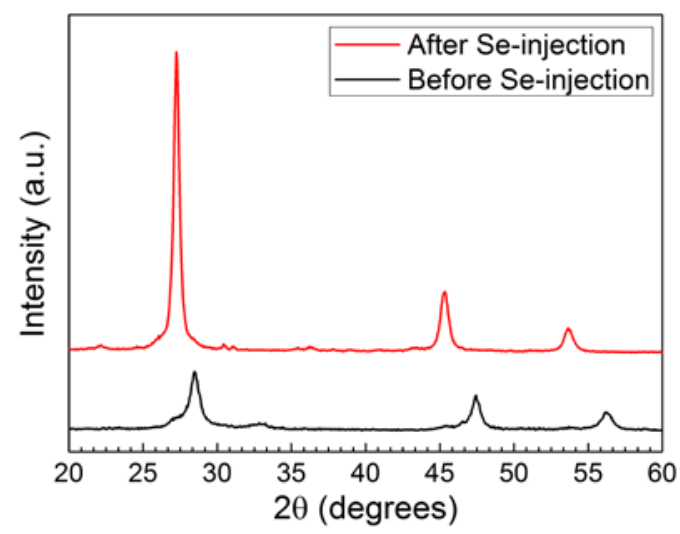

(a)

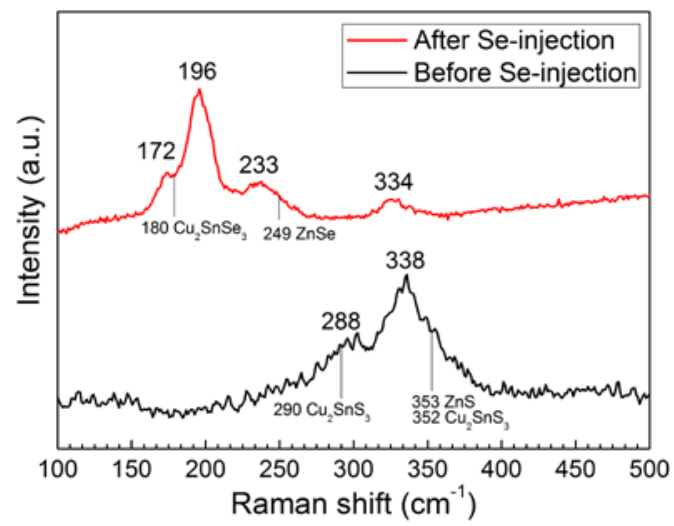

(b)

Figure 1. (a) XRD pattern for CZTS prepared at $220^{\circ} \mathrm{C}$ for 20 min and CZTSe prepared at $250^{\circ} \mathrm{C}$ for $2 \mathrm{hr}$ after Se-injection. The $2 \theta$ diffraction peak positions for CZTS are $28.48^{\circ}, 32.90^{\circ}$, $47.43^{\circ}$, and $56.25^{\circ}$. The peaks for CZTSe are at $27.25^{\circ}, 36.20^{\circ}$, $45.28^{\circ}$, and $53.66^{\circ}$. (b) Raman spectra before and after Se- 
injection. CZTS NPs were prepared at $220^{\circ} \mathrm{C}$ for $20 \mathrm{~min}$ and CZTSe NPs at $260^{\circ} \mathrm{C}$ for $2 \mathrm{hr}$.

Phase analysis. Fig. 1(a) shows the powder XRD pattern for nanoparticles before and after the injection of selenium. The $2 \theta$ diffraction peak positions of the material before Seinjection are at $28.48^{\circ}, 32.90^{\circ}, 47.43^{\circ}$ and $56.25^{\circ}$; and after Seinjection, the peak positions shifted to lower values, $27.25^{\circ}$, $36.20^{\circ}, 45.28^{\circ}$ and $53.66^{\circ}$. These peaks correspond to the (112), (200), (220), and (312) plane reflections for zinc blende CZTS (JCPDS no. 26-0575) and (112), (105), (204), and (312) for CZTSe (JCPDS no. 70-8930), respectively. The shoulders on the main zinc blende (112) peaks can be assigned to wurtzite (10o) and (101) planes. ${ }^{33}$ Since the CZTS peaks overlap with $\mathrm{ZnS}$ (JCPDS no. 26-1619, 36-1450, 05-0566) and $\mathrm{Cu}_{2} \mathrm{SnS}_{3}$ (JCPDS no. 27-0198, 35-0648), and the CZTSe peaks overlap with $\mathrm{ZnSe}$ (JCPDS no. 37-1463) and $\mathrm{Cu}_{2} \mathrm{SnSe}_{3}$ (JCPDS no. 657524), it is difficult to conclude if there are any binary phases from the XRD pattern. However the Raman spectra in Fig. (b) show no signs of any secondary phases.

The $A_{1}$ Raman mode frequency for the CZTS and CZTSe phases can be observed at $338.5 \mathrm{~cm}^{-1}$ and $196 \mathrm{~cm}^{-1}$ respectively, (Fig. 1(b)). The additional Raman peaks at $288 \mathrm{~cm}^{-1}$ before Se-injection and $172 \mathrm{~cm}^{-1}$ and $233 \mathrm{~cm}^{-1}$ after Se-injection also corresponds to the CZTS and CZTSe phases ${ }^{39}$. The main ZnS Raman peak should be seen at $353 \mathrm{~cm}^{-1}$, the $\mathrm{Cu}_{2} \mathrm{SnS}_{3}$ at 290 $\mathrm{cm}^{-1}$ and $352 \mathrm{~cm}^{-1}$, the ZnSe at $249 \mathrm{~cm}^{-1}$ and the $\mathrm{Cu}_{2} \mathrm{SnSe}_{3}$ at $18 \mathrm{o} \mathrm{cm}^{-1}$, when measured with the same laser wavelength $\mathrm{h}^{3-41}$. There is a possibility that small amounts of these secondary phases might be present, especially in the pure sulfide phase, however the Raman spectrum does not provide any evidence of these secondary phases. This two-step synthesis method therefore offers good control of the conversion and produces pure phase material, with no secondary phases present within the detection limit of the XRD and Raman analysis.

The XRD patterns and the Raman spectra reveal that the injection of Se in TOP into a mixture of CZTS NPs resulted in a transformation from CZTS to CZTSe. As pointed out earlier, the Bragg angles for CZTSe are shifted to lower values compared to CZTS because CZTSe has a larger lattice-spacing than CZTS due to the larger Se atoms replacing the $\mathrm{S}$ atoms. The XRD patterns of the (112)-reflection peak for samples obtained at different reaction times are plotted in Fig. 2. As the reaction takes place, a shift in the peak positions from the CZTS phase to the CZTSe phase occurs. After $10 \mathrm{~min}$ of reaction the (112) "CZTSe" peak is at $27.37^{\circ}$, and shifts to $27.34^{\circ}$ after $30 \mathrm{~min}$, and $27.25^{\circ}$ after $60 \mathrm{~min}$. This indicates that Se-rich mixed-phase CZTSSe material is formed, but with small amounts of S. The Raman spectrum in Fig. 1(b) also supports this observation, as the small peak at $334 \mathrm{~cm}^{-1}$ after Se-injection is an indication that there are small amounts of S present in the CZTSSe phase ${ }^{39}$. One possible reason why only little $S$ is included is that the enthalpy for the mixed-phase CZTSSe is higher than CZTS and CZTSe, and in the liquid phase the mobility of the atoms is high and hence the exchange is quite substantial. Riha et al. ${ }^{5}$ also found that the reactivities of the precursors are crucial when synthesizing mixed-phase CZTSSe; if the reactivities of Sand Se-precursors were not properly balanced, phase separation would occur.

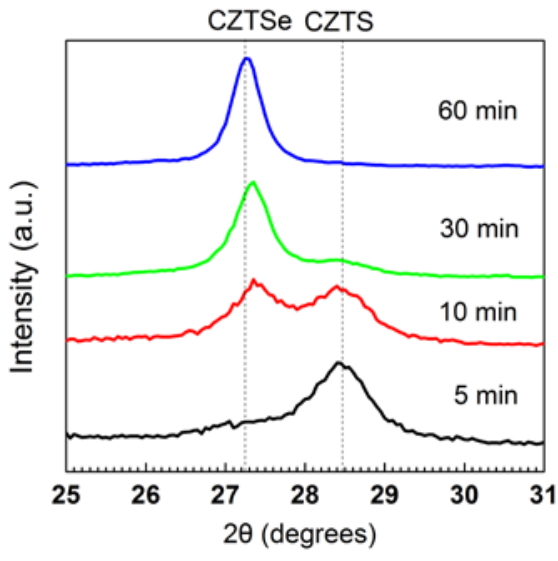

Figure 2. XRD pattern centered at the (112)-reflection kesterite peak for various reaction times. After $10 \mathrm{~min}$ reaction there is a mixture of CZTS and CZTSe particles.

EDX measurements were carried out for all powders, and the composition as a function of time after Se-injection is shown in Fig. 3, with the elemental distribution shown in Fig. $3(\mathrm{a})$ and the $[\mathrm{Cu}] /([\mathrm{Zn}]+[\mathrm{Sn}]),[\mathrm{Zn}] /[\mathrm{Sn}]$, and $[\mathrm{Se}] /([\mathrm{Se}]+[\mathrm{S}])-$ ratios plotted in Fig. 3(b). The nanoparticles are either CZTS or CZTSe, however if a thin film was formed from these particles, a mixed phase material would be created after annealing. Based on the EDX results, two minutes after Seinjection, the $[\mathrm{Se}] /([\mathrm{S}]+[\mathrm{Se}])$ ratio was $2 \%$ and two hours after Se-injection it was $86 \%$. This conversion can also be quantified using the area under the (112)-reflection in the XRD pattern, and compared to the EDX data (can be seen in Table S.1.). The XRD pattern after $1 \mathrm{hr}$ shows that all CZTS is converted to CZTSe, however the EDX data only show $82 \%$ conversion. One reason for this discrepancy could be that the CZTS NPs are poorly crystallized and the newly formed CZTSe NPs are more crystalline as compared to the CZTS NPs, or that some $\mathrm{S}$ is incorporated in the "CZTSe" phase as seen from the XRD and Raman measurements.

The rate of transformation from CZTS to CZTSe is fastest at the beginning of the reaction and saturates after about 1 hr. The $[\mathrm{Se}] /([\mathrm{S}]+[\mathrm{Se}])$ ratio is identical to the $[$ CZTSe]/([CZTS]+[CZTSe]) ratio when assuming no significant mixed sulfide/selenide phase is present. As the reaction progressed, more CZTSe is formed as one would expect; however saturation occurs when the ratio of CZTSe is $86 \%$. Some of the best CZTSSe solar cells have $[\mathrm{Se}] /([\mathrm{Se}]+[\mathrm{S}])-$ ratios of $0.6 \pm 0.1,{ }^{42}$ and $0.87,{ }^{43}$ and by simply varying the duration of the reaction, these ratios can be achieved. The nanoparticles are initially $\mathrm{Zn}$-rich and $\mathrm{Cu}$-poor but as the reaction goes on one notes that there is a loss of $\mathrm{Zn}$ and gain of $\mathrm{Cu}$. In order to maintain $\mathrm{Zn}$-rich and $\mathrm{Cu}$-poor conditions in the final film, KCN etching can be used to remove any unwanted $\mathrm{Cu}_{2}$ Se phase. $^{44}$ 


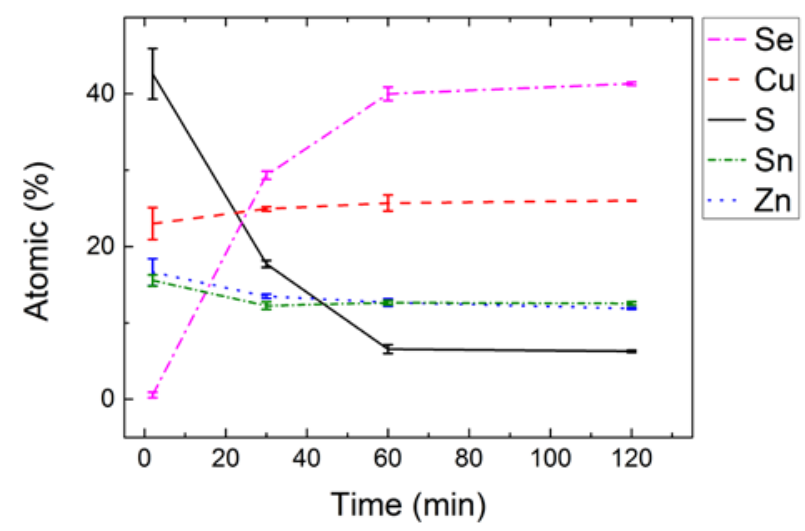

(a)

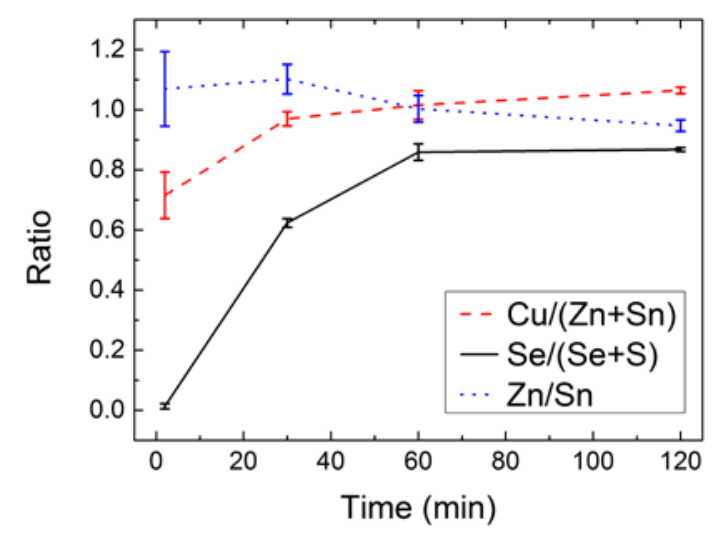

(b)

Figure 3. Atomic (a) percentages and (b) ratios versus time after Se-injection, at $250^{\circ} \mathrm{C}$ and $1.33 \mathrm{M}$ Se.

Study on injected Se-concentration. The optimum concentration of injected Se for particle growth was determined based on measuring the composition of the particles. In Fig. 4, the composition as a function of the injected Seconcentration is shown, and it was found that more $S$ is exchanged by Se as the injected Se-concentration increases. Note that the $\mathrm{Cu}, \mathrm{Zn}$ and $\mathrm{Sn}$ atomic percentages remain rather constant. After $30 \mathrm{~min}$ of reaction time, the ratio of CZTS converted to CZTSe increases at higher injected Seconcentrations. In general, looking at Fig. 4(b), it can be seen that for this liquid phase selenization method, the substitution of S to Se seems to approach saturation after $2 \mathrm{M}$ of Se.

In order to observe changes on a suitable time scale, a concentration of $1.33 \mathrm{M}$ was chosen for the following study because the composition seems to show saturation at this concentration.

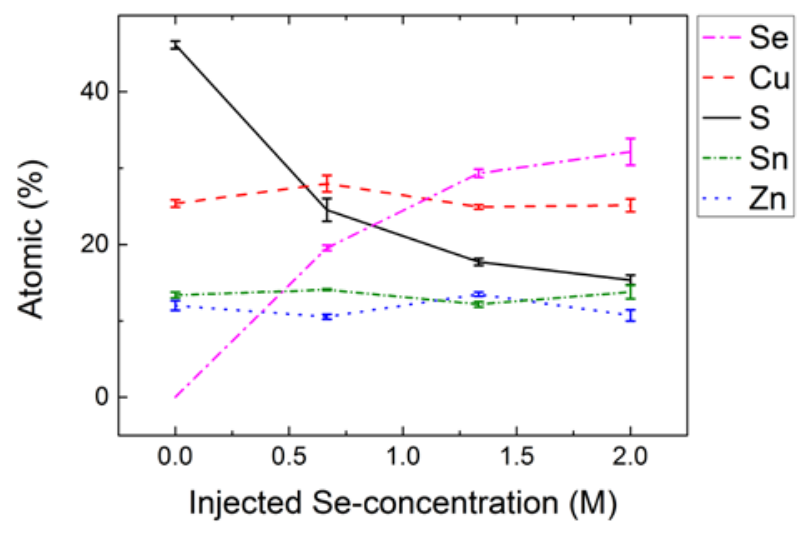

(a)

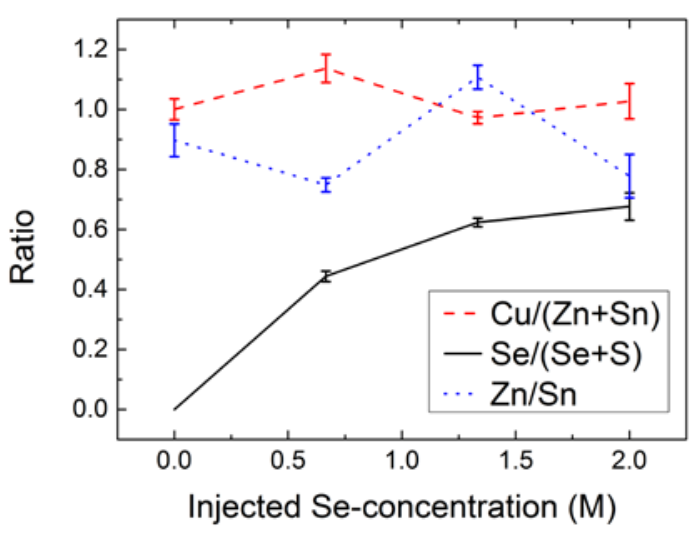

(b)

Figure 4. Atomic (a) percentages and (b) ratios as a function of injected Se-concentration, at $250^{\circ} \mathrm{C}$ for $30 \mathrm{~min}$.

Particle growth. Fig. 5 shows TEM images of the particles over time after Se-injection. The largest particle size after 2 min was $30 \mathrm{~nm}$ and this increased to $80 \mathrm{~nm}$ after $30 \mathrm{~min}$ and finally to $116 \mathrm{~nm}$ after $4 \mathrm{hr}$ (Fig. S.1.). The average particle size changes from $15 \pm 7 \mathrm{~nm}$ after $2 \mathrm{~min}$, to $66 \pm 11 \mathrm{~nm}$ after $30 \mathrm{~min}$, to $56 \pm 21 \mathrm{~nm}$ after $4 \mathrm{hr}$, indicating the presence of a few large particles with many small nanoparticles at longer reaction times. The large particles were found to be Se-rich, and the small ones S-rich.

In order to conclusively rule out the impact of the solvent/ligand on the particle growth, the CZTS NP solution was heated while injecting only TOP. The average CZTS particle size estimated from Fig. S.2(a) and (b) was 13.3 \pm 4.1 $\mathrm{nm}$ and $15.5 \pm 5.2 \mathrm{~nm}$, respectively. Thus no significant particle growth occurs without the addition of Se.

The main focus in the literature until now has been to achieve a narrow size distribution in order to form a compact film. ${ }^{15}$ Applying size-selective methods, could possibly isolate the large particles. ${ }^{45}$ However, perhaps a better packing density can be achieved from having a mixture of large and small NPs. 


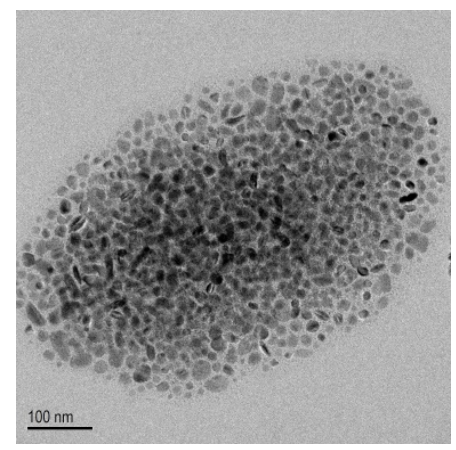

(a)

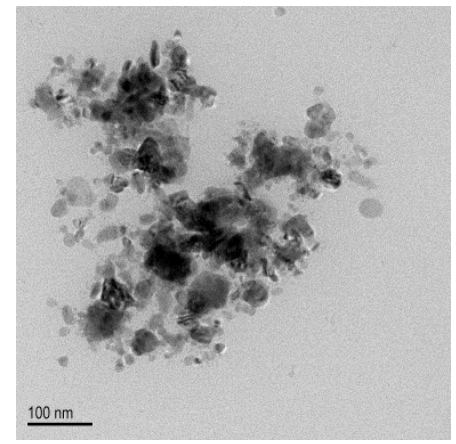

(e)

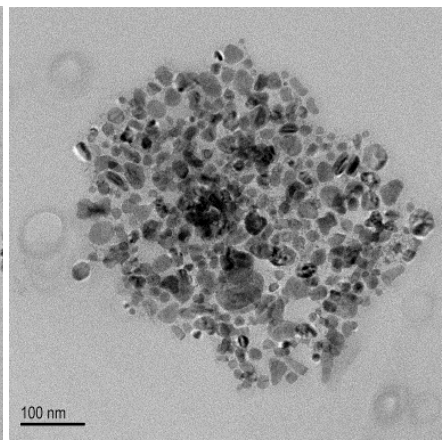

(b)

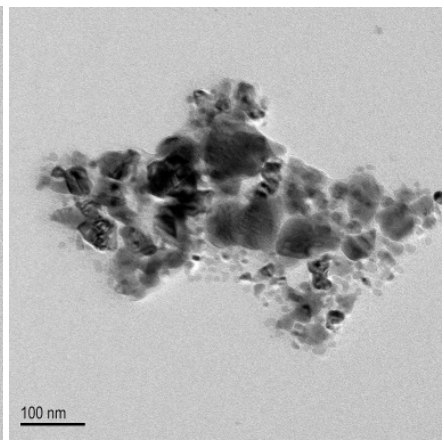

(f)

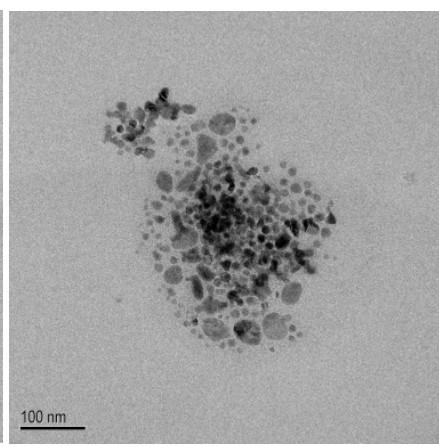

(c)

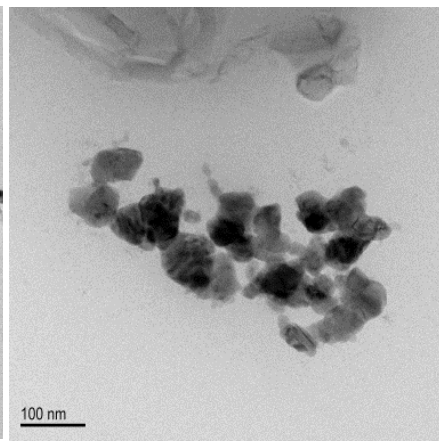

(g)

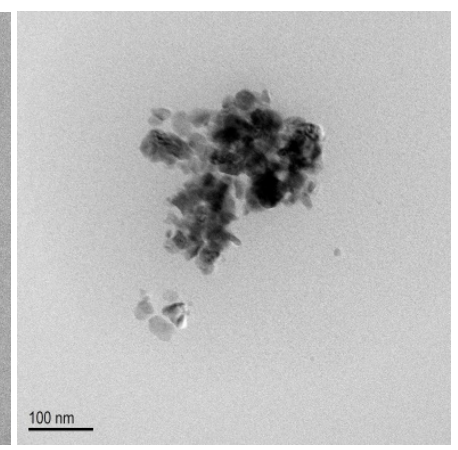

(d)

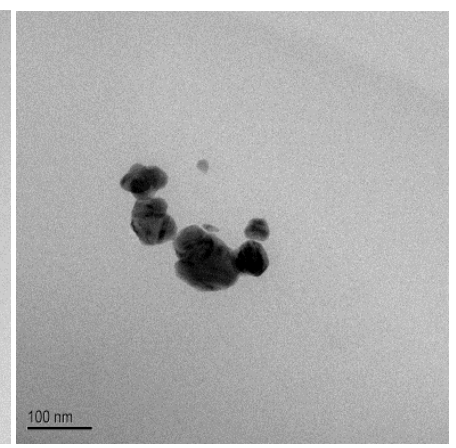

(h)

Figure 5. TEM images of particle growth in time after Se-injection, at $250^{\circ} \mathrm{C}$ and $1.33 \mathrm{M} \mathrm{Se}$. (a) $2 \mathrm{~min}$, (b) $5 \mathrm{~min}$, (c) $10 \mathrm{~min}$, (d) 20 min, (e) $30 \mathrm{~min}$, (f) $1 \mathrm{hr},(\mathrm{g}) 2 \mathrm{hr}$, and (h) $4 \mathrm{hr}$.

Even larger particles can be synthesized by optimizing the synthesis conditions. By changing the temperature and amount of Se injected, the CZTSe particles grow to almost $500 \mathrm{~nm}$ (showed in Fig. S.3.), and by using a solvent with a higher boiling point than hexadecane, even higher synthesis temperatures would be possible. These findings are very relevant for synthesizing large NPs through the hot-injection method, and more focus can be put on this approach in the future to control the particle size.

Nanoparticle formation mechanism. Nanoparticle growth typically occurs in two steps: initially, the precursors, i.e. the salts, transform into active monomers (here metal cations and chalcogenide anions or their corresponding reactive complexes) that nucleate in a supersaturated solution, followed by a growth process. The growth occurs by monomer diffusing onto the nuclei either directly from the solution or at the expense of other smaller particles as they have higher surface energy - Ostwald ripening. Ostwald ripening describes the process when smaller particles shrink and larger ones grow. ${ }^{46}$ Both the surfactant molecules, the precursors and the solvent affect the processes of nucleation and growth, and this complex process is still not well understood. ${ }^{38}$

In our case, we see the formation of a few large and highly crystalline CZTSe NPs together with many smaller CZTS NPs, as illustrated in Fig. 6. We suggest that when Se-TOP is injected, the CZTS NPs decompose into monomers, leading to nucleation and growth to form CZTSe NPs. In the initial phase the high concentration of monomers may lead to an enhanced growth of small CZTSe-particles. This will soon continue as Ostwald ripening. As no core/shell-structure was detected by STEM-EDX (Fig. S.4), we assume that new nucleation of CZTSe occurs.

Yin and Alivisatos' model ${ }^{38}$ of kinetic size control can be used to explain this; their model describes the growth rate as a function of particle size for low and high monomer concentrations. They introduce a critical size, above which particles grow and below which they redissolve. For high monomer concentrations the critical size is smaller than for low monomer concentrations. Furthermore, the growth rate for high monomer concentrations is faster for smaller particles, which results in size focusing. For low monomer concentrations, on the other hand, the growth rate is not changing much, leading to a wider distribution of particles. Our design of experiment ensures that at the time of Se-injection, we have nanoparticles and only very few free cation monomers are available, which leads to few nuclei being created with a high critical size. Fewer CZTSe nuclei initially means more monomers available from the CZTS NPs per nuclei, and thus larger CZTSe nanoparticles.

During the course of the reaction, we assume that the CZTS NPs decompose, which leads to a release of metal cations and chalcogenide anions. The electron affinity of S (200 $\mathrm{kJ} / \mathrm{mol})$ is higher than that of Se $(195 \mathrm{~kJ} / \mathrm{mol})^{47}$, which results in more $S$ to be reduced to reactive sulfide. This may explain why CZTS is redissolved to a greater extent than CZTSe.

In addition, the stability of the compound depends on the enthalpy of formation, $\Delta H_{f}$, which is lower for CZTSe than CZTS. ${ }^{33}$ In other words, CZTSe is the more stable compound, which explains why the large particles consist of CZTSe. 
Fig. 7 shows a schematics of how the monomer concentration could vary during the synthesis of CZTS NPs (curve I), and during the conversion of CZTS NPs to CZTSe NPs (curve II). Growth of the CZTS NPs occurs after a quick nucleation with a high monomer concentration, and the particle distribution is relatively monodisperse at the end of the reaction. Converting CZTS NPs to CZTSe NPs on the other hand, occurs at a low monomer concentration, but with a constant release of monomers throughout the reaction. LaMer and Dinegar state that the final particle size and the rate of growth depend on three factors: (1) the number of nuclei, (2) the total amount of diffusible monomers, and (3) the diffusion coefficient of the monomers in the medium. ${ }^{48}$ The number of nuclei and the amount of mobile monomers are thus what allow us to synthesize large particles.

\section{Synthesis of CZTS NP ink}

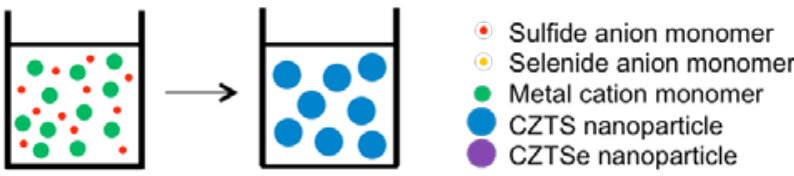

\section{Conversion of CZTS to CZTSe NPS}

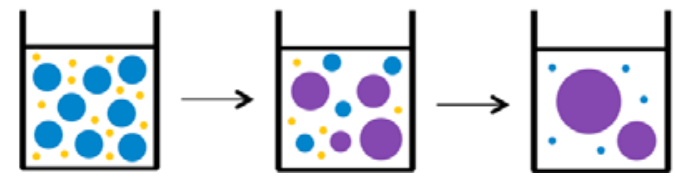

Figure 6. The proposed formation mechanism for hotinjection of Se into CZTS NPs. The outer shell of atoms on the CZTS NPs is constantly in a dynamic equilibrium with monomers (ions) in the solution. As Se is injected, a nucleation and growth occur favoring the CZTSe phase. As the reaction is allowed to go on, the CZTSe NPs grow larger at the expense of the smaller CZTS NPs.

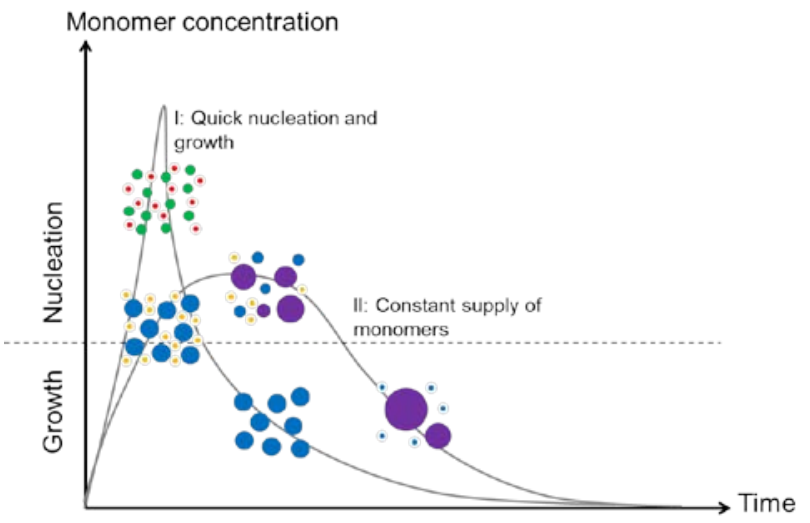

Figure 7. Monomer concentration as a function of time, where curve I is based on the well-known model by LaMer and Dinegar: $:^{48}$ After a single nucleation event a uniform growth by diffusion occurs. Curve II depicts what could happen in our case: Initially, we have a low monomer concentration and thus few nuclei with a high critical size. Thereafter, we have a constant supply of monomers, which allows the formation of large particles. Symbols are explained in Fig. 6.

We have found that it is difficult to control the transformation of CZTS into mixed-phase CZTSSe while injecting Se-
TOP at a temperature of less than $300^{\circ} \mathrm{C}$. The CZTSSe NPs synthesized will always be Se-rich. To limit the decomposition of the CZTS NPs and to trigger the formation of mixedphase CZTSSe particles, lower amounts of Se or a mixture of $\mathrm{S} / \mathrm{Se}$ can be injected. Currently the injected Se concentration far exceeds the $S$ concentration in the solution. Alternatively, using a more slowly reacting Se-precursor could aid in avoiding a phase-separated system, as seen by Riha et al. ${ }^{5}$ Another possibility would be to initially synthesize CZTS with TOP as surfactant, and then inject Se in oleylamine. This might limit the decomposition of CZTS and perhaps avoid phase separation. Finally, one could also synthesize mixed CZTSSe NPs using this synthetic route by starting with CZTSe and injecting $\mathrm{S}$.

There may be many routes to control the monomer concentration, but this is the first of its kind for CZTS/CZTSe NPs.

\section{Conclusion}

The growth of CZTS/CZTSe nanoparticles can be controlled by the reaction duration, the reactivity of the chalcogenide precursors or controlling the monomer concentration. In the present work we describe how to control the monomer concentration in the solution by starting out with a mixture of CZTS nanoparticles and injecting Se. Introducing a high concentration of Se in the liquid phase as a kind of liquid selenization can result in approx. $500 \mathrm{~nm}$ CZTSe particles. The generation of the large particles is a consequence of the initial low monomer concentration, as well as the fact that the CZTSe phase is more stable than CZTS, and that there is a supply of monomer from the original CZTS NPs.

This approach can be used to create a mixture of large and small nanoparticles, which could favor the packing of particles for a film. Furthermore, the ratio of CZTS to CZTSe can be carefully tuned simply by varying the reaction time.

\section{Acknowledgement}

This work has been supported by The Danish Council for Strategic Research.

\section{References}

1 W. Wang, M.T. Winkler, O. Gunawan, T. Gokmen, T.K. Todorov, Y. Zhu and D.B. Mitzi, D. B. Adv. Energy Mater. 2014, 4 (7), 1301465.

2 S. Tajima, T. Itoh, H. Hazama, K. Ohishi and R. Asahi, Appl. Phys. Express 2015, 8, 082302.

3 Y.S. Lee, T. Gershon, O. Gunawan, T.K. Todorov, T. Gokmen, Y. Virgus and S. Guha, Adv. Energy Mater. 2014, 1401372. 4 Q. Guo, H.W. Hillhouse and R. Agrawal, J. Am. Chem. Soc. 2009, 131, 11672-11673.

5 S.C. Riha, B.A. Parkinson and A.L. Prieto, J. Am. Chem. Soc. 2011, 133, 15272.

6 W. Liu, D.B. Mitzi, M. Yuan, A.J. Kellock, S.J. Chey and O. Gunawan, Chem. Mater. 2010, 22, 1010-1014.

7 C.K. Miskin, W.-C. Yang, C.J. Hages, N.J. Carter, S.C. Joglekar, E.A. Stach and R. Agrawal, Prog. Photovolt: Res. Appl. 2014, DOI: 10.1002/pip.2472.

8 J. van Embden, A.S.R. Chesman, E.D. Gaspara, N.W. Duffy, S.E. Watkins and J.J. Jasieniak, J. Am. Chem. Soc. 2014, 136, 5237-5240. 
9 A. Carrete, A. Shavel, X. Fontané, J. Montserrat, J. Fan, M. Ibáñez, E. Saucedo, A. Pérez-Rodríguez and A. Cabot, J. Am. Chem. Soc. 2013, 135 (43), 15982-15985.

10 X. Lin, J. Kavalakkatt, N. Brusten, M.C. Lux-Steiner and A. Ennaoui, 29th European Photovoltaic Solar Energy Conference and Exhibition 2014, 1876-1879.

11 E. M. Mkawi, K. Ibrahim, M.K.M. Ali, M.A. Farrukh and N.K. Allam, Chem. Phys. Lett. 2014, 6o8, 393-397.

12 R. Mainz, B.C. Walker, S.S. Schmidt, O. Zander, A. Weber, H. Rodriguez-Alvarez, J. Just, M. Klaus, R. Agrawal and T. Unold, Phys. Chem. Chem. Phys. 2013, 15, 18281-18289. 13 Y. Cao, M.S. Denny, J.V. Caspar, W.E. Farneth, Q. Guo, A.S. Ionkin, J.K. Johnson, M. Lu, I. Malajovich, D. Radu, H.D. Rosenfeld, K.R. Choudhury and W. Wu, J. Am. Chem. Soc. 2012, 134, 15644-15647.

14 M. Kauk, K. Muska, M. Altosaar, J. Raudoja, M. Pilvet, T. Varema, K. Timmo and O. Volobujeva, Energy Procedia 2011, 10, 197-202.

15 H. Zhou, W.-C. Hsu, H.-S. Duan, B. Bob, W. Yang, T.-B. Song, C.-J. Hsu and Y. Yang, Energy Environ. Sci. 2013, 6, 2822.

16 Y.-L. Zhou, W.-H. Zhou, Y.-F. Du, M. Li and S.-X. Wu, Materials Letters 2011, 65, 1535-1537.

17 W. Xie, X. Jiang, C. Zou, D. Li, J. Zhang, J. Quan and L. Shao, Physica E 2012, 45, 16-20.

18 O. Zaberca, F. Oftinger, J.Y. Chane-Ching, L. Datas, A. Lafond, P. Puech, A. Balocchi, D. Lagarde and X. Marie, Nanotechnology 2012, 23, 185402.

19 Q. Tian, X. Xu, L. Han, M. Tang, R. Zou, Z. Chen, M. Yu, J. Yang and J. Hu, CrystEngComm 2012, 14, 3847-3850. 20 Y.-L. Zhou, W.-H. Zhou, M. Li, Y.-F. Du and S.-X. Wu, J. Phys. Chem. C 2011, 115, 19632-19639.

21 R.B.V. Chalapathy, G.S. Jung, Y.M. Ko, B.T. Ahn and H.S. Kown, Current Photovoltaic Research 2013, 1(2), 109-114 . 22 S.C. Riha, B.A. Parkinson and A.L. Prieto, J. Am. Chem. Soc. 2009, 131(34), 12054-12055.

23 C. Steinhagen, M.G. Panthani, V. Akhavan, B. Goodfellow, B. Koo and B.A. Korgel, J. Am. Chem. Soc. 2009, 131(35), 12554-12555.

24 A. Shavel, J. Arbiol and A. Cabot, J. Am. Chem. Soc. 2010, 132, 4514-4515.

25 A. Khare, A.W. Wills, L.M. Ammerman, D.J. Norris and E.S. Aydil, Chem. Commun. 2011, 47, 11721-11723.

26 C. Zou, L. Zhang, D. Lin, Y. Yang, Q. Li, X. Xu, X. Chen and S. Huang, CrystEngComm. 2011, 13, 3310.

27 M. Li, W.-H. Zhou, J. Guo, Y.-L. Zhou, Z.-L. Hou, J. Jiao, Z.-J. Zhou, Z.-L. Du and S.-X. Wu, J. Phys. Chem. C 2012, 116, 26507-26516.

28 A. Singh, H. Geaney, F. Laffir and K.M. Ryan, J. Am.

Chem. Soc. 2012, 134, 2910-2913.

29 T. Rath, W. Haas, A. Pein, R. Saf, E. Maier, B. Kunert, F. Hofer, R. Resel and G. Trimmel, Solar Energy Materials $\mathcal{E}$ Solar Cells 2012, 101, 87-94.

30 M. Zhou, Y. Gong, J. Xu, G. Fang, Q. Xu and J. Dong, Journal of Alloys and Compounds 2013, 574, 272-277.

31 B. Hou, D. Benito-Alifonso, N. Kattan, D. Cherns, M.C. Galan and D.J. Fermín, Chem. Eur. J. 2013, 19, 15847 - 15851. 32 Y. Li, Q. Han, T.W. Kim and W. Shi, Nanoscale 2014, 6, 3777 .

33 Z. Li, A.L.K. Lui, K.H. Lam, L. Xi and Y.M. Lam, Inorg.

Chem. 2014, 53, 10874-10880.

34 E. Gu, C. Yan, F. Liu, Y. Liu, Z. Su, K. Zhang, Z. Chen, J. Li and Y. Liu, J. Mater. Sci.: Mater. Electron, 2015, 26, 1932-1939. 35 A. L. Patterson, Phys. Rev. 1939, 56, 978-982.
36 A. Panácek, L. Kvitek, R. Prucek, M. Kolar, R. Vecerova, N. Pizurova, V. K. Sharma, T. Nevecna and R. Zboril, J. Phys. Chem. B 2006, 110, 16248-16253.

37 I. Sondi, D. V. Goia and E. Matilvic, Journal of Colloidal and Interface Science 2003, 260, 75-81.

38 Y. Yin and A.P. Alivisatos, Nature 2005, 437(29), 664-670. 39 M. Grossberg, J. Krustok, J. Raudoja, K. Timmo, M. Altosaar and T. Raadik Thin Solid Films 2011, 519, 7403-7406. 40 X. Fontané, L. Calvo-Barrio, V. Izquierdo-Roca, E. Saucedo, A. Pérez-Rodriguez, J. R. Morante, D. M. Berg, P. J. Dale and S. Siebentritt Appl. Phys. Lett. 2011, 98, 181905. 41 M. Altosaar, J. Raudoja, K. Timmo, M. Danilson, M. Grossberg, J. Krustok and E. Mellikov phys. stat. sol. (a) 2008, 205 (1), 167-170.

42 D.A.R. Barkhouse, O. Gunawan, T. Gokmen, T.K. Todorov and D.B. Mitzi, Prog. Photovolt: Res. Appl. 2012, 20, 6-11. 43 T. Schnabel, M. Löw and E. Ahlswede, Solar Energy Materials \& Solar Cells 2013, 117, 324-328.

44 T. Tanaka, T. Sueishi, K. Saito, Q. Guo, M. Nishio, K.M. Yu and W. Walukiewicz, J. Appl. Phys. 2012, 111, 053522. 45 C.B. Murray, D.J. Norris and M.G. Bawendi, J. Am. Chem. Soc. 1993, 115 (19), 8706-8715.

46 L. Ratke and P.W. Voorhees, in Growth and Coarsening: Ripening in Material Processing, Springer, New York, 2002, pp. 1-300.

47 CRC Handbook of Chemistry and Physics, $96^{\text {th }}$ Ed., CRC Press, FL, 2015-2016, pp. 10.147-148.

48 C.B. Murray, C.R. Kagan and M.G. Bawendi, Annu. Rev. Mater. Sci. 2000, 30, 545-610. 


\section{Supporting Information}

\section{Percentage of conversion}

The percentage of conversion from CZTS to CZTSe is calculated from the areas under the XRD peaks of the (112)-reflections, and compared to the EDX data in Table S.1. The amount of conversion is larger from the XRD data, where $100 \%$ conversion is assumed for the film formed using the particles obtained after 60 min of reaction and that the amount of mixed-phase sulfide/selenide material is negligible.

Table S.1. Percentage of conversion from CZTS to CZTSe calculated from XRD and EDX measurements: From the area under the (112)-reflection in the XRD pattern in Fig. 2 (where the peak area for 6o min is set equal to $100 \%$ ), and extracted from a fit to the EDX curve in Fig. $3(\mathrm{~b})$.

\begin{tabular}{l|cc} 
& \multicolumn{2}{|c}{ Percentage of conversion (\%) } \\
Reaction time (min) & XRD & EDX \\
\hline \hline 5 & 33.1 & 12.5 \\
10 & 46.6 & 28.4 \\
30 & 84.5 & 64.5 \\
60 & 100 & 81.6
\end{tabular}

\section{Particle size}

The particle size as a function of time was determined from the TEM images in Fig. 5, and is displayed in Fig. S.1. A polydisperse particle size distribution is observed, and both the average size of large particles, small particles, and all particles are plotted.

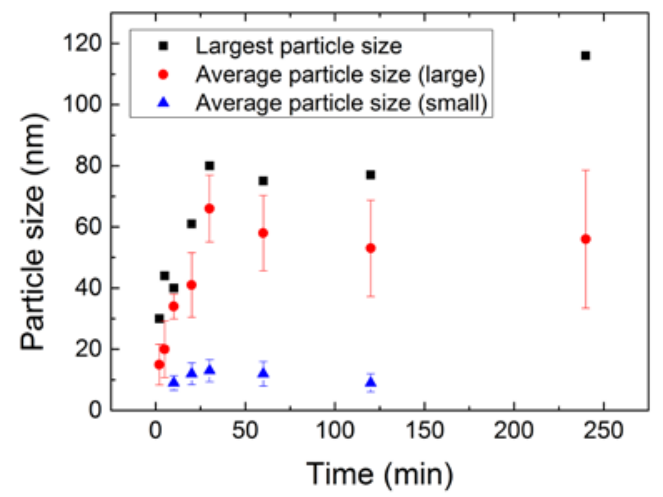

Figure S.1. Average particle size measured from TEM images synthesized at $250^{\circ} \mathrm{C}$ with $1.33 \mathrm{M}$ Se. A bimodal distribution of particle sizes is seen for most cases.

\section{Influence of surfactant}

A TEM image of the nanoparticles obtained just before Se-injection is shown in Figs. S.2(a), i.e. after reaction at $220^{\circ} \mathrm{C}$ for $20 \mathrm{~min}$. Fig. S.2(b) shows these CZTS NPs after only TOP injection. The NPs in Fig. S.2(a) were precipitated by centrifugation and re-dispersed in hexadecane, followed by injection of TOP without Se and heated at $250^{\circ} \mathrm{C}$ for 30 min and the NPs are showed in Fig. S.2(b).

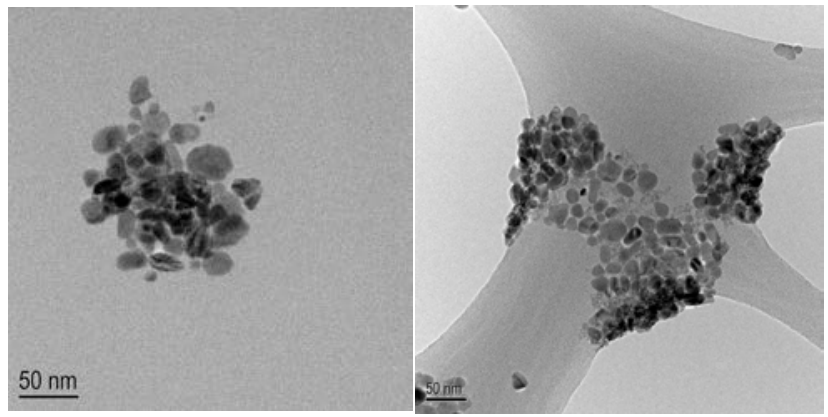


(a)

(b)

Figure S.2. TEM images of CZTS NPs after (a) 20 min reaction at $220^{\circ} \mathrm{C}$, and (b) after 50 min reaction with TOP injection. This is the result of a reference experiment to see if TOP alone would initiate grain growth of the CZTS NPs. In the case of (b), the reaction was stopped after 20 min and started again with injection of TOP (without Se) for $30 \mathrm{~min}$.

\section{Larger particles}

We have also studied particle growth at $230^{\circ} \mathrm{C}$ and o.66 M Se (Fig. S.3(a)) and at $260^{\circ} \mathrm{C}$ and 1 M Se (Fig. S.3(b)). The distinct faceted shapes of the Se-rich particles imply a highly crystalline material, and after $1 \mathrm{~h}$ reaction at $260^{\circ} \mathrm{C}$ and $1 \mathrm{M}$ Se the largest particle size was approaching $0.5 \mu \mathrm{m}$ in diameter.

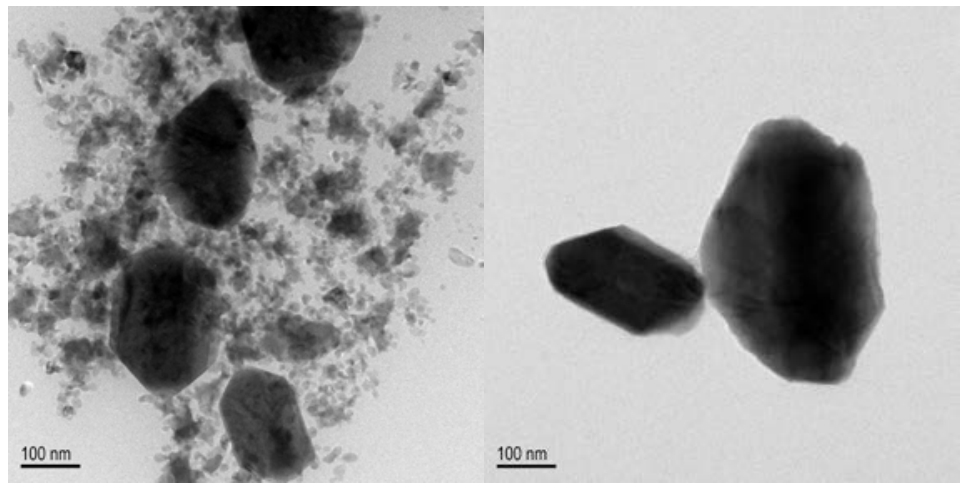

(a)

(b)

Figure S.3. TEM image of CZTSe particles grown for (a) $2 \mathrm{hr}$ after Se-injection, at $230^{\circ} \mathrm{C}$ and $0.66 \mathrm{M} \mathrm{Se}$, and (b) $1 \mathrm{hr}$ after Se-injection, at $260^{\circ} \mathrm{C}$ and $1 \mathrm{M}$ Se. These reaction conditions result in very large particles, approaching $500 \mathrm{~nm}$.

\section{Elemental map}

The STEM-EDX elemental map in Fig. S.4 shows the NPs after Se-injection, and it supports the XRD results. The large particles are Se-rich, and the S-signal can come either from small S-rich NPs aggregating on the surface of the large particles, or from a small amount of S inside the Se-rich particles, as the XRD and Raman analysis also suggest. No sign of a core/shell-structure is observed.

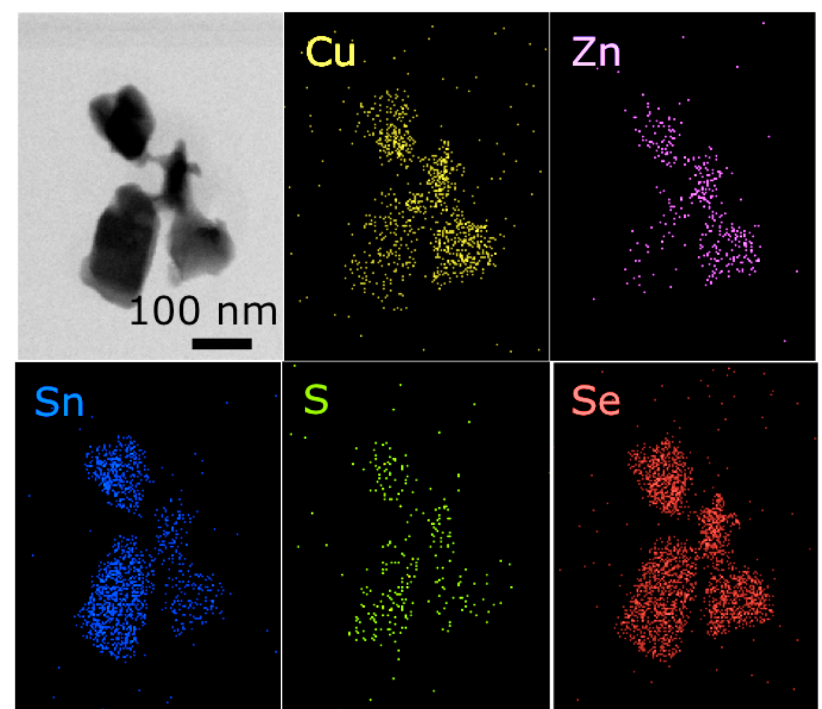

Figure S.4. STEM-EDX elemental map of NPs heated at $260^{\circ} \mathrm{C}$ for 30 min after Se-injection. 